\title{
Plutonium and Minor Actinides Recycling in Standard BWR using Equilibrium Burnup Model
}

\author{
Abdul Waris ${ }^{1}$, Rizal Kurniadi \& Zaki Su’ud \\ Nuclear Physics and Biophysics Research Group, Faculty of Mathematics and Natural \\ Sciences, Bandung Institute of Technology \\ Center for Nuclear Applications, Bandung Institute of Technology \\ Jl. Ganesa 10 Bandung, 40132, Indonesia \\ ${ }^{1}$ E-mail: awaris@fi.itb.ac.id
}

\begin{abstract}
Plutonium (Pu) and minor actinides (MA) recycling in standard BWR with equilibrium burnup model has been studied. We considered the equilibrium burnup model as a simple time independent burnup method, which can manage all possible produced nuclides in any nuclear system. The equilibrium burnup code was bundled with a SRAC cell-calculation code to become a coupled cellburnup calculation code system. The results show that the uranium enrichment for the criticality of the reactor, the amount of loaded fuel and the required natural uranium supply per year decrease for the Pu recycling and even much lower for the Pu \& MA recycling case compared to those of the standard oncethrough BWR case. The neutron spectra become harder with the increasing number of recycled heavy nuclides in the reactor core. The total fissile rises from $4.77 \%$ of the total nuclides number density in the reactor core for the standard once-through BWR case to $6.64 \%$ and $6.72 \%$ for the Plutonium recycling case and the Pu \& MA recycling case, respectively. The two later data may become the main basis why the required uranium enrichment declines and consequently diminishes the annual loaded fuel and the required natural uranium supply. All these facts demonstrate the advantage of plutonium and minor actinides recycling in BWR.
\end{abstract}

Keywords: BWR; equilibrium burnup; harder neutron spectrum; minor actinides; plutonium; recycling.

\section{$1 \quad$ Introduction}

Soon after the end of the cold war, the plutonium $(\mathrm{Pu})$ issue surface up since there were many war-heads should be dismantled from the US and Russian's nuclear missiles. This was due to the escalation in large amount of the plutonium stockpile that must be handled. One way to overcome this burden is to utilize this excess plutonium in the present commercial power reactors, i.e., pressurized light water reactor (PWR), boiling water reactor (BWR), pressurized heavy water reactor (PHWR/CANDU), or gas cooled type reactors. Feasibility study on utilization or recycling of plutonium has been conducted since 1975 [1] and starting for implementation in PWR and BWR from the

Received April, 2006, Revised September, 25 ${ }^{\text {nth }}, 2006$, Accepted for publication September, 25 $5^{\text {nth }}, 2006$. 
second-half of 1990s decade, either in France, UK or Japan [2]. Plutonium in the war-head comes from a spent fuel of nuclear power plants (NPP). A part of plutonium, NPP's spent fuel also contains minor actinides (MA). In fact, MA is not merely waste, but it can be used as a nuclear fuel likes uranium and plutonium so that we can extend the time spend of the uranium utilization. However, research on MA recycling in the existing commercial NPP has not been well studied, especially in BWR. The study on the plutonium and MA recycling in PWR up to cell calculation level has been conducted by one of the author $[3,4]$. Some research projects concerning Pu and MA management in PWR was just started during the last two years $[5,6]$. These evidences inspire us to contribute in performing study on plutonium and minor actinides recycling in BWR.

\section{Methodology}

As a preliminary research, this study is aimed at evaluating the characteristics of plutonium and minor actinide recycled in BWR by using a nuclear equilibrium state burnup model, which has been introduced and intensively used in our previous studies concerning PWR [3, 4]. We considered the equilibrium burnup model as a powerful method for nuclear system characteristic's prediction as it can handle all possible generated nuclides in any nuclear system of more than 1350 nuclides.

The above burnup model was described in detail [3, 4], and briefly can be summarized as follows. The density of any nuclide in the reactor is continually changing due to nuclear reactions such as radioactive decay, fission, and neutron capture. This change influences reactor core multiplication factor, power distributions as well as flux level. The time dependent of the number density of $i$-th nuclide, $n_{i}$, in the reactor core for the standard fuel burnup can be expressed as in the following Eq. (1).

$$
\frac{d n_{i}}{d t}=-\left(\lambda_{i}+\phi \sigma_{a, i}+r_{i}\right) n_{i}+\sum_{j} \lambda_{j \rightarrow i} n_{j}+\phi \sum_{k} \sigma_{k \rightarrow i} n_{k}+s_{i}
$$

where $\phi$ : neutron flux, $\lambda_{i}$ : decay constant of $i$-th nuclide, $r_{i}$ : discharge constant of $i$-th nuclide, $\lambda_{j \rightarrow i}$ : decay constant of $j$-th nuclide to produce $i$-th nuclide, $\sigma_{k \rightarrow i}:$ microscopic transmutation cross-section of $k$-th nuclide to produce $i$-th nuclide, $s_{i}$ : supply rate of $i$-th nuclide, $\sigma_{a, i}$ : microscopic absorption crosssection of $i$-th nuclide. 
The production of fission products can be estimated by substituting $\sigma_{k \rightarrow i}$ in the Eq. (1) with the following equation:

$$
\sigma_{k \rightarrow i}=\sigma_{f, k} \gamma_{k \rightarrow i}
$$

where $\sigma_{f, k}$ : microscopic fission cross-section of $k$-th nuclide, $\gamma_{k \rightarrow i}$ : yield of $i$ th nuclide from $k$-th fissile nuclide.

Assuming that the fuel loading process is a continuous process and the number density of each nuclide in the reactor is constant, then the standard fuel burnup goes to the nuclear equilibrium-state burnup model. Consequently, the number density of $i$-th nuclide, $n_{i}$, in the reactor core for this situation should satisfy the following equation:

$$
\left(\lambda_{i}+\phi \sigma_{a, i}+r_{i}\right) n_{i}-\sum_{j} \lambda_{j \rightarrow i} n_{j}-\phi \sum_{k} \sigma_{k \rightarrow i} n_{k}=s_{i}
$$

The Eq. (3) is solved by using our equilibrium burnup code. This equilibrium burnup code should then be bundled with a SRAC [7] cell-calculation code to become a coupled cell-burnup calculation code system. We have employed 1368 nuclides in the equilibrium burnup calculation with 129 of them are heavy metals (HMs) and the rest are fission products (FP). For both calculation schemes, the JENDL 3.2 library has been used [8].

Core design parameters of studied BWR are presented in Table 1. Here we assumed that the efficiency of the reactor is $33 \%$, so that the electric power output is 1000 MWe. The other parameters in the Table 1 represent the design parameter of the General Electric's BWR/6 reactor.

In order to obtain a more widespread view of the evaluated system, we have chosen the following three scenarios to be investigated. They are:

1. A standard BWR case in which the BWR core is loaded with uranium oxide (UOX) fuel without recycling of any nuclide. This case is also called UOX case.

2. A plutonium recycling case that is the BWR core loaded with UOX fuel and the produced plutonium from the reactor is directly recycled into the reactor without cooling process.

3. A plutonium and minor actinides recycling case, in which the BWR core is loaded with UOX fuel and the produced plutonium and minor actinides from the reactor are directly recycled into the reactor without cooling process. 
Tabel 1 Core design parameters of studied BWR.

\begin{tabular}{lc}
\hline Thermal power output & $3000 \mathrm{MWth}$ \\
Average power density & $59 \mathrm{Wcm}^{-3}$ \\
Radius of fuel pellet & $0.529 \mathrm{~cm}$ \\
Radius of fuel rod & $0.615 \mathrm{~cm}$ \\
Pin pitch & $1.444 \mathrm{~cm}$ \\
Void coefficient & $42 \%$ \\
Fuel type & Oxide \\
Cladding & Zircaloy-2 \\
Coolant & $\mathrm{H}_{2} \mathrm{O}$ \\
\hline
\end{tabular}

\section{$3 \quad$ Calculation Results and Discussion}

In this study we have chosen fuel cycle length is 36 months. One-third of the total fuel in the reactor core is loaded or discharged annually. Table 2 shows the required enrichment and amount of required natural uranium that should be supplied in a year for each investigated scenario. The required uranium enrichment for the standard BWR case is about $5.15 \mathrm{w} \%$, which is quite higher than that of the standard BWR with the standard burnup model. This higher enrichment may due to the larger power density in this study of about 59 watt/cc. As a matter of perspective, the required uranium enrichment for BWR with the standard burnup model is about $2.9 \mathrm{w} \%$ with the power density is 50 watt/cc. The uranium enrichment for the criticality of the reactor decreases considerably for the Pu recycling and even much lower for the Pu and MA recycling case compared to the standard BWR case. A similar tendency was also shown in the required natural uranium per annum. The annual requirement of natural uranium was calculated by assuming that the uranium concentration in the tail of the enrichment plant is $0.2 \mathrm{w} \%$. These two facts demonstrate that the $\mathrm{Pu}$ recycling and the $\mathrm{Pu} \& \mathrm{MA}$ recycling can be worth for the uranium saving. In other words, plutonium and minor actinides really can be considered as the nuclear fuel instead of uranium. The amount of loaded fuel slightly reduces with the increasing number of recycled nuclides from the standard BWR case up to the Pu \& MA recycling case. This is another advantage of recycling. The burnup increases from that of the standard BWR case up to the $\mathrm{Pu} \& \mathrm{MA}$ recycling case as a result of the reduction of the loaded fuel. Here, the burnup means the amount of produced energy (GWd) from one ton of loaded fuel. 
Tabel 2 The required enrichment and amount of required natural uranium.

\begin{tabular}{cccccc}
\hline Case & $\begin{array}{c}\text { Enrichment } \\
\text { (wt\%) }\end{array}$ & $\begin{array}{c}\text { Loaded } \\
\text { fuel } \\
\text { (t/yr) }\end{array}$ & $\begin{array}{c}\text { Burnup } \\
\text { (GWd/t) }\end{array}$ & $\begin{array}{c}\text { Required } \\
\text { Natural } \mathbf{U} \\
\mathbf{( t / y r )}\end{array}$ & $\begin{array}{c}\text { Flux } \\
\left(\# / \mathbf{c m}^{-2} \cdot \mathbf{s}^{-\mathbf{1}}\right)\end{array}$ \\
\hline $\begin{array}{c}\text { Standard } \\
\text { BWR }\end{array}$ & 5.15 & 57.95 & 18.90 & 560.89 & $2.95 \mathrm{E}+14$ \\
$\begin{array}{c}\text { Pu-recycling } \\
\text { Pu \& MA- } \\
\text { recycling }\end{array}$ & 2.24 & 53.99 & 20.30 & 215.32 & $3.01 \mathrm{E}+14$ \\
\hline
\end{tabular}

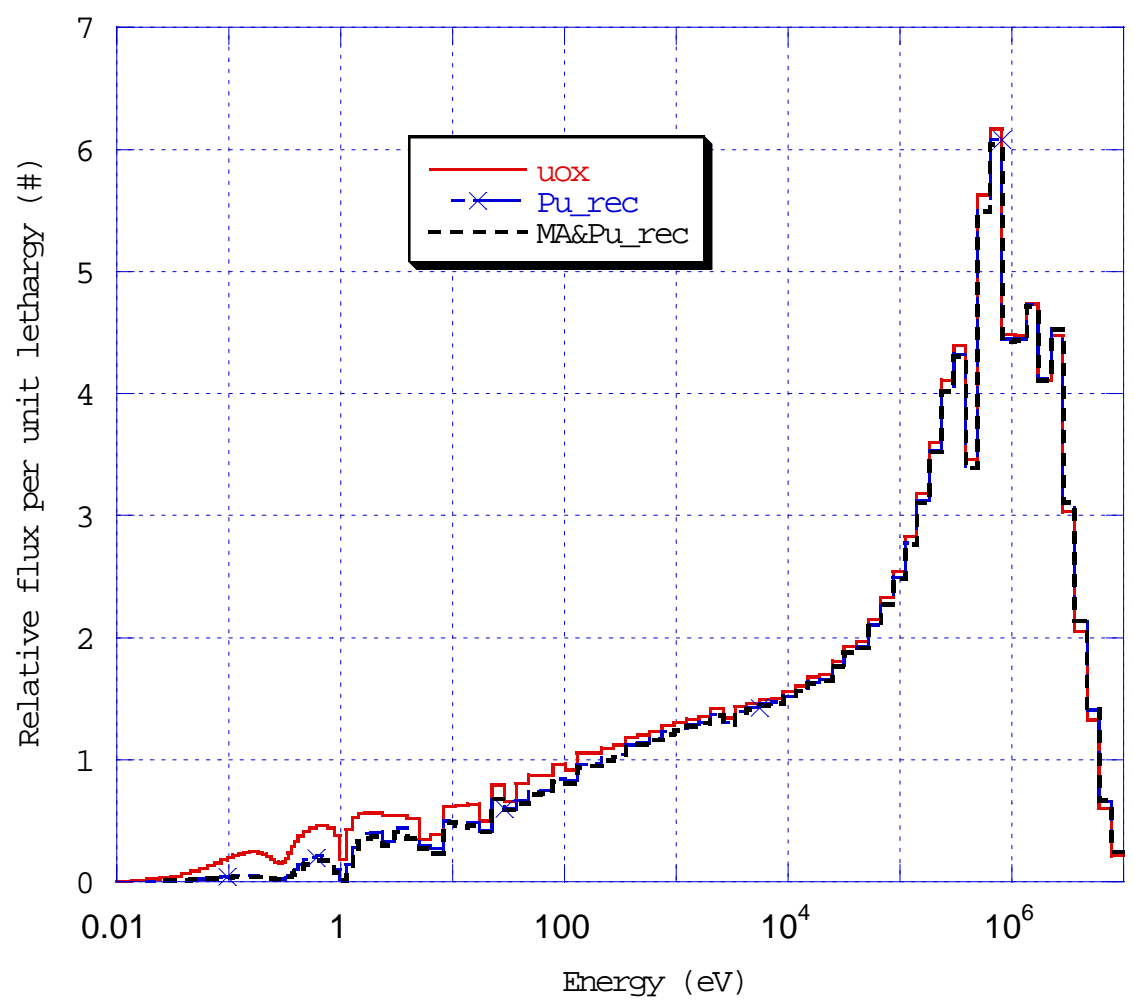

Figure 1 Neutron spectra of all evaluated cases.

Figure 1 shows a neutron spectrum of each evaluated case. The neutron spectrum is shifted to the higher energy region with the increasing number of recycled nuclides from the standard BWR case up to the $\mathrm{Pu} \& \mathrm{MA}$ recycling case. In other words, the neutron spectrum becomes harder with the rising number of recycled heavy nuclides in the reactor core. The other clue of the spectrum hardening is the increment of the neutron flux from $2.95 \times 10^{14}$ 
(neutrons $/ \mathrm{cm}^{-2} \cdot \mathrm{s}^{-1}$ ) for the standard BWR case to $3.01 \times 10^{14}$ (neutrons $/ \mathrm{cm}^{-2} \cdot \mathrm{s}^{-1}$ ), and $3.03 \times 10^{14}$ (neutrons $/ \mathrm{cm}^{-2} . \mathrm{s}^{-1}$ ) for the Pu recycling and Pu \& MA recycling cases, correspondingly, as shown in Table 2. This aspect was also shown in our previous study [4]. As a matter of perspective, 107 energy groups that consist of 61 fast energy groups and 46 thermal energy groups have employed for the cellcalculation. These energy groups then were collapsed into one group of energy.

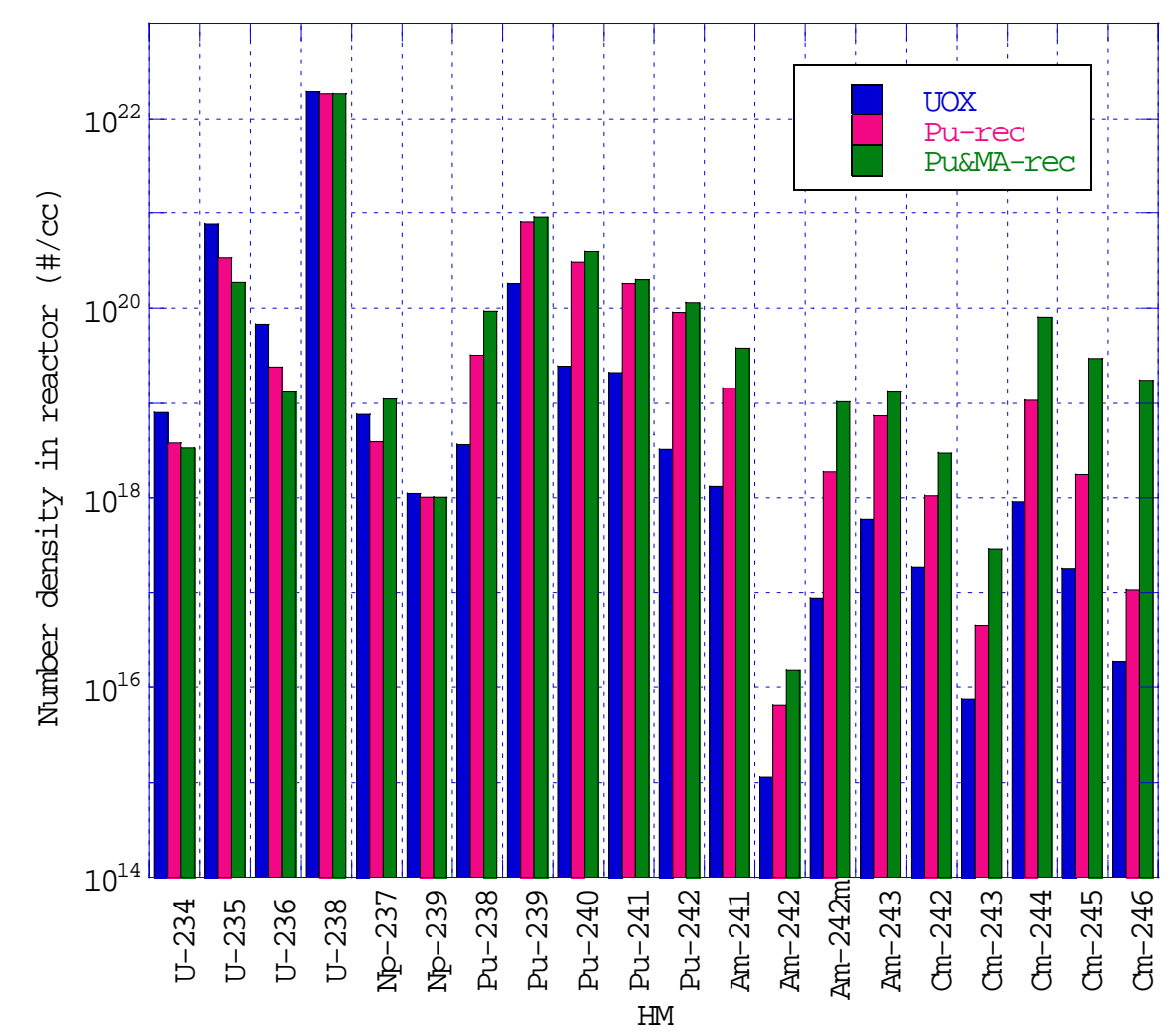

Figure 2 Number density of selected HM for all evaluated cases.

Figure 2 shows the number density of selected heavy metals (HM) of each evaluated case. As the number density of the plutonium isotopes and minor actinide nuclides in the reactor core increase for the plutonium and the $\mathrm{Pu} \&$ MA recycling cases compared to the standard BWR case, the number density of uranium fuel nuclides (U-234, U-235, U-238) decrease monotonically. This is due to the decrement of the required uranium enrichment. 
A fissile nuclide is a nuclide that can undergo a thermal neutron induced fission reaction. In general, an actinide member of nuclide with the atomic number of more than 90 and with the odd neutron number can be considered as the fissile nuclide, i.e., U-233, Am-242, and Cm-245. The fissile plutonium consists of $\mathrm{Pu}-239$ and $\mathrm{Pu}-241$ isotopes. The recycling of plutonium and/or minor actinides will not impact logically in the increment of the fissile plutonium, even worse the fissile plutonium decreases with the increasing number of recycled heavy metals in the reactor core. This fact was shown clearly in the Figure 3. This figure shows a plutonium vector, which is the composition of the plutonium isotopes (Pu-238, Pu-239, $\mathrm{Pu}-240, \mathrm{Pu}-241$, and $\mathrm{Pu}-242$ ) in percent. The plutonium vector of the UOX, the Pu-recycling, and the Pu \& MA recycling cases are $1.57 \%, 77.6 \%, 10.5 \%, 8.93 \%, 1.39 \%$; $2.24 \%, 57.0 \%, 21.7 \%, 12.7 \%$, $6.35 \%$; and $5.45 \%, 52.9 \%, 23.2 \%, 11.8 \%, 6.69 \%$; respectively. The percentage of the fissile plutonium for the above mentioned consecutive cases are: $86.6 \%$, $69.7 \%$, and $64.6 \%$, correspondingly.

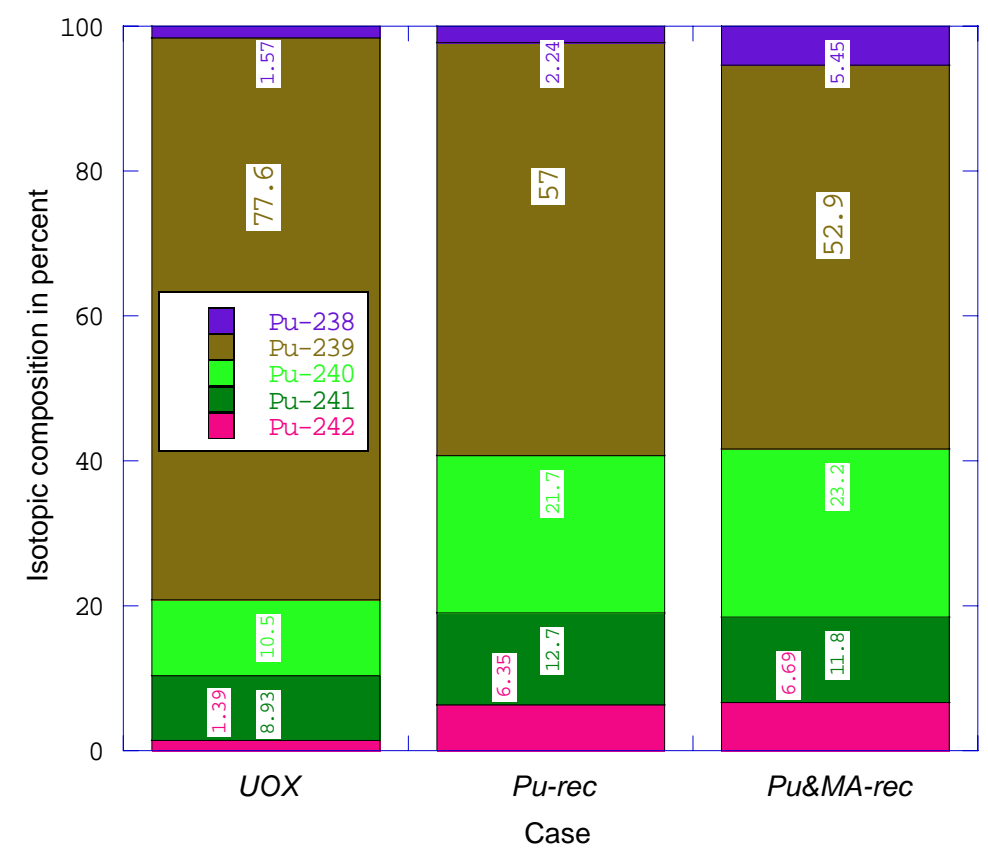

Figure 3 Plutonium vector of all evaluated cases.

On the other hand, the percentage of the fissile minor actinides (Am-242, Am$242 \mathrm{~m}, \mathrm{Cm}-243$, and $\mathrm{Cm}-245$ ) raises from $2.3 \%$ for the UOX case to $8.76 \%$ and $19.7 \%$ for the plutonium recycling and the $\mathrm{Pu} \& \mathrm{MA}$ recycling cases, respectively. This evidence is shown in Figure 4, which presenting the minor actinides vector of all evaluated cases. The main contributors for the increment 
of the fissile minor actinides from the UOX case to the Pu \& MA recycling case are $\mathrm{Am}-242 \mathrm{~m}$ and $\mathrm{Cm}-245$. The Am-242m increases from $0.73 \%$ in the UOX case to $4.5 \%$ and $5.0 \%$ in the Plutonium case and the $\mathrm{Pu} \& \mathrm{MA}$ case, respectively. Moreover, the $\mathrm{Cm}-245$ boosts from $1.5 \%$ in the UOX case to $4.17 \%$ and $14.6 \%$ in the plutonium recycling case and the Pu \& MA recycling case, correspondingly.

The inflating of the fissile minor actinides may become the main benefactor in the lessening of the required uranium enrichment and consequently diminishes the annual loaded fuel and the required natural uranium supply. In more detail explanation, the fissile uranium (U-235) trim down from 3.77\% of the total nuclides number density in the reactor core for the UOX case to $1.68 \%$ and $0.92 \%$ for the plutonium recycling case and the $\mathrm{Pu} \& \mathrm{MA}$ recycling case, respectively. The fissile trans-uranium (the fissile plutonium + minor actinides) lifts up from $1.0 \%$ for the UOX case to $4.96 \%$ and $5.8 \%$ for the plutonium recycling case and the $\mathrm{Pu} \& \mathrm{MA}$ recycling case, correspondingly. In overall, the total fissile (the fissile uranium + plutonium + minor actinides) increase from $4.77 \%$ for the UOX case to $6.64 \%$ and $6.72 \%$ for the plutonium recycling case and the Pu \& MA recycling case, respectively.

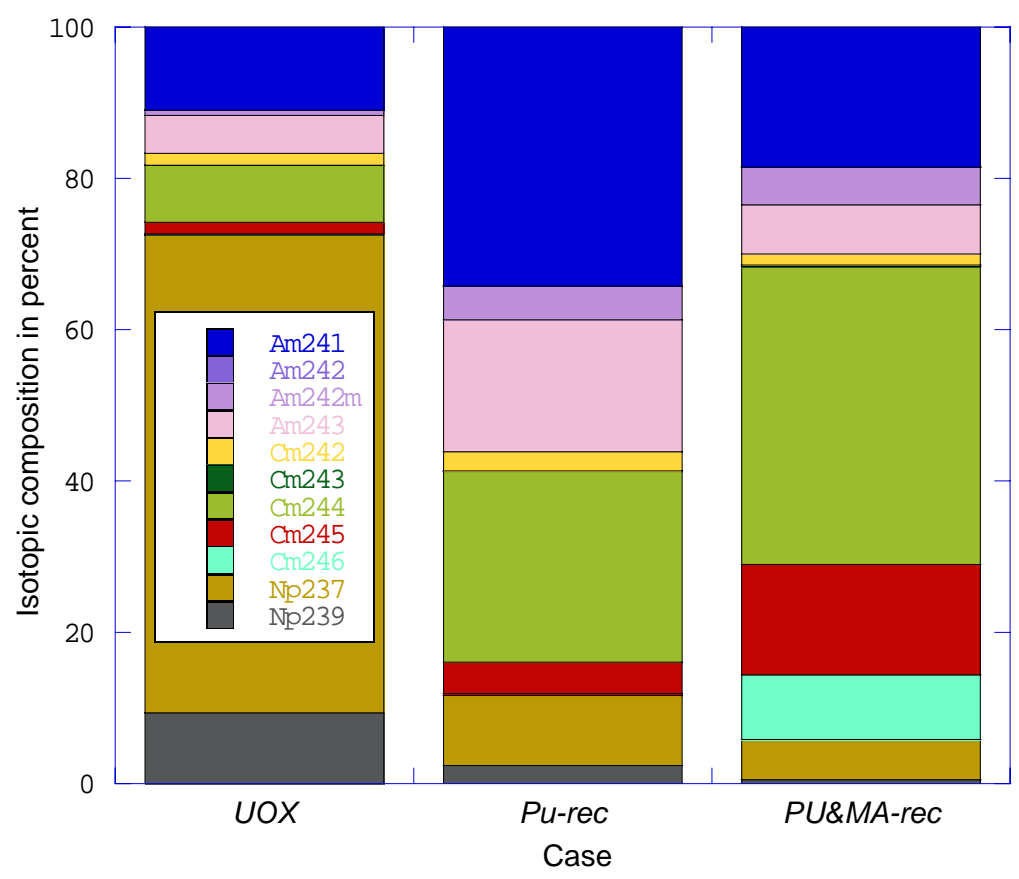

Figure 4 Minor actinides vector of all evaluated cases. 


\section{Conclusions}

Study on plutonium and minor actinides recycling in standard BWR with equilibrium burnup model has been conducted. The uranium enrichment for the criticality of the reactor decreases considerably for the Pu recycling and the $\mathrm{Pu}$ and MA recycling case compared to the standard BWR case. The comparable propensity was also shown in the annual required natural uranium. The amount of loaded fuel reduces to some extent with the rising number of recycled nuclides in the reactor from the standard BWR case up to the $\mathrm{Pu} \& \mathrm{MA}$ recycling case. These all facts demonstrate the beneficial of plutonium and minor actinide recycling. The neutron spectrum increased with the growing number of recycled heavy nuclides in the reactor core. The total fissile expands from $4.77 \%$ of the total nuclides number density in the reactor core for the UOX case to $6.64 \%$ and $6.72 \%$ for the plutonium recycling case and the Pu \& MA recycling case, correspondingly. The two later proofs may become the main reason why the required uranium enrichment declines and consequently diminishes the annual loaded fuel and the required natural uranium supply.

\section{Acknowledgement}

This research is fully funded by ITB Research Grant No. 0076/K01.03/PL2.1.5/VI/2005

\section{References}

[1] Edlund, M.C., High Conversion Ratio Plutonium Recycle in Pressurized Water Reactors, Ann. Nuclear Energy, 2, 801, 1975.

[2] Leventhal, P. \& Dolley, S., Understanding Japan's Nuclear Transports: The Plutonium Context, Proc. Conf. on Carriage of Ultrahazardous Radioactive Cargo by Sea: Implications and Responses, Kuala Lumpur, Malaysia, 1999.

[3] Waris, A. \& Sekimoto, H., Basic Study on Characteristics of several equilibrium fuel cycles of PWR, Ann. Nuclear Energy, 28, 153, 2001.

[4] Waris, A. \& Sekimoto, H., Characteristics of Several Equilibrium Fuel Cycles of PWR, J. Nucl. Sci. Technol., 38, 517, 2001.

[5] http://www.neri.ne.doe.gov/2006Awards/NERI\%2006-065.pdf.

[6] http:// www.pnl.gov/ineri/eu_awards04.html.

[7] Okumura, K., et al., SRAC (Ver.2002): The Comprehensive Neutronics Calculation Code System, Japan Atomic Energy Research Institute, Tokai-mura, Japan, 2002.

[8] Nakagawa, T., et al., Japanese Evaluated Nuclear Data Library Version 3 Revision-2: JENDL-3.2, J. Nucl. Sci. Technol., 32, 1259, 1996. 